\title{
SOBRE POETAS E PENSADORES: UMA CONVERSA SOBRE FILOSOFIA, LITERATURA E A RECONSTRUÇÃO DO MUNDO ${ }^{1}$
}

\author{
Costica Bradatan; Simon Critchley; Giuseppe Mazzotta; Alexander Nehamas ${ }^{2}$ \\ Tradução por Djeissom Silva Ribeiro ${ }^{3}$
}

Às vezes pode haver algo extremamente sedutor acerca do incerto e do impreciso. Em uma ocasião, o antigo sábio chinês Chuang Chou fez esta perturbadora confissão, que deve ter deixado seus discípulos muito perplexos: "Uma vez, Chuang Chou sonhou que era uma borboleta, uma borboleta voando e tremulando em movimento circular, feliz consigo mesmo e fazendo o que gostava. Ele não sabia que era Chuang Chou. Repentinamente, ele acordou e lá estava, o sólido e inconfundível Chuang Chou. Mas ele não sabia se ele era Chuang Chou e sonhara que era uma borboleta, ou uma borboleta sonhara que era Chuang Chou". O distinto charme filosófico da situação em que Chuang Chou se encontrava parece vir, precisamente, da imprecisão estrutural na qual está baseada. Qualquer tentativa de fixa-la certamente a prejudicaria; este charme existe apenas e tão-somente enquanto permanece relacionada à correspondente ambiguidade. A única maneira apropriada de lidar com tal situação consiste precisamente em "deixa-la ser", a considerar sua imprecisão como algo dado.

De muitas maneiras, a relação entre Filosofia e Literatura não é diferente daquela entre Chuang Chou e a borboleta com a qual sonhara ser: sua intensa atratividade origina-se, precisamente, da imprecisão na qual está baseada e a qual, não é preciso dizer, é, em si mesma, um problema filosófico digno da mais séria consideração. Para discutir as charmosas e ambíguas relações entre a Filosofia e a Literatura eu convidei três renomados estudiosos de Filosofia e Literatura: Simon Critchley, Professor and Chair of Philosophy at The New School for Social Research; Giuseppe Mazzotta, Sterling Professor in the Humanities for Italian at Yale University e Alexander Nehamas, Professor in the Humanities at Princeton University. (C. B.).

\footnotetext{
${ }^{1} \mathrm{O}$ texto foi publicado originalmente na revista The European Legacy, Vol. 14, No. 5, pp. 519-534, 2009, sob o título: Of poets and Thinkers. A Conversation on Philosophy, Literature, and the Re-building of the World.

2 Costica Bradatan, The Honors College, Texas Tech University, Lubbock, TX 79401, USA. E-mail: costica.bradatan@ttu.edu

Simon Critchley, 321 1/2 State St., Brooklyn, NY 11217, USA. E-mail: critchls@ newschool.edu

Giuseppe Mazzotta, Yale University, Department of Italian, New Haven, CT 06520, USA. E-mail: giuseppe.mazzotta@yale.edu

Alexander Nehamas, 692 Pretty Brook Road, Princeton, NJ 08540, USA. E-mail: nehamas@ princeton.edu

${ }^{3}$ Professor Adjunto da Universidade Federal do Recôncavo da Bahia - UFRB.
} 
Costica Bradatan: Em primeiro lugar, eu gostaria de agradecer vocês três por gentilmente aceitarem participar nesta conversa. Eu sei o quão ocupados todos vocês são e eu estou muito agradecido a vocês por encontrar tempo para participar.

Eu gostaria de começar com uma determinada observação que me intrigou por algum tempo. É sobre uma suposição amplamente difundida na principal corrente filosófica da atualidade (especialmente no mundo da língua inglesa) que os aspectos literários de um texto filosófico, em geral, não significam nada, que eles não tem - e não deveriam ter - qualquer papel significativo na produção, interpretação e apreciação desse texto. É como se um texto filosófico fosse (ou pudesse ser facilmente considerado) algo perfeitamente transparente, como se você pudesse "ver absolutamente tudo através dele", sem ter de considerar sua literariedade. A literariedade de um texto filosófico é, de acordo com esta visão predominante, perfeitamente insignificante, algo que se pode facilmente deixar de lado e, ainda assim, o significado desse texto permanecerá intacto. Houve um tempo, não muito distante, quando os filósofos (um Bergson, por exemplo) poderiam receber um Prêmio Nobel de Literatura. Hoje, em alguns círculos, se você elogiar os filósofos pelas qualidades literárias de seus escritos, eles podem muito bem entender como uma crítica disfarçada. Como vocês comentam esse estado de coisas? De onde se origina? O que vocês pensam sobre esta tendência?

Simon Critchley: Deixe-me responder sobre a relação entre a Filosofia e a Literatura contando uma história. Eu me lembro de ter dado uma palestra no departamento de filosofia de uma renomada universidade inglesa, a qual a modéstia me impede mencionar. Eu estava com quase 30 anos de idade e era muito inexperiente em dar palestras. O período de questionamentos da palestra foi muito agitado e levemente hostil, eu me lembro. No jantar, logo após a palestra, um filósofo de uma corrente muito diferente da minha disse, em resposta a algumas considerações que fizera durante os questionamentos, "Eu não vejo porque ler o texto de um filósofo não seja exatamente igual a sentar-se para jantar com ele". O exemplo que ambos tínhamos em mente era Descartes. Eu destaquei o fato de que Descartes, provavelmente, não fosse fluente em inglês, de que vivera há 400 anos em um contexto cultural e histórico muito diferente e realmente explosivo, definido pela Guerra dos Trinta Anos, da qual era participante, que ele escrevera em diferentes estilos em seus textos em Latim e em sua língua vernácula e realizara constantes experiências com a forma literária, usando a meditação Jesuítica, os relatos autobiográficos de Montaigne e, até mesmo, conhecido por haver terminado sua carreira escrevendo os versos para um balé, conforme solicitação da Rainha Christina da Suécia. Após terminar minha fala, meu interlocutor 
fez o óbvio e disse, "Isto está muito bem colocado de uma perspectiva histórica e literária, mas o que importa é a verdade ou a inverdade dos argumentos de Descartes".

Aí está o preconceito, da forma como você diz em sua pergunta, no fato de que podemos ler através da superfície de um texto filosófico e julgar seus argumentos como válidos ou inválidos. A série de livros que resume esta abordagem é aquela editada pela Routledge, "Argumentos dos Filósofos", que eu acredito tenha sido primeiro editada por Freddie Ayer, embora eu possa estar equivocado. A pressuposição desta abordagem é que apenas os argumentos são importantes e que nós podemos ignorar as características históricas, retóricas, linguísticas, culturais e literárias de um texto como se fossem irrelevantes detalhes de superfície que é melhor ignorar. Eu discordo veementemente desta abordagem. Os argumentos são, obviamente, muito importantes, mas nós ignoramos aquelas outras características por nossa conta e risco e, quando as ignoramos, nós arriscamos cair em uma abordagem filistéia, muito surpreendente acerca dos textos filosóficos. Se a Filosofia é exclusivamente baseada em argumentos, então como explicamos o fato de que existem tantos argumentos pobres em muitos textos filosóficos, a começar com os diálogos de Platão? Platão era estúpido?

Eu acredito que nós tenhamos chegado a um estado de coisas muito peculiar quando os filósofos são observados com suspeição porque eles escrevem muito bem.

Alexander Nehamas: A Filosofia Analítica (eu vou me limitar a esse assunto aqui) é um movimento Modernista - G. E. Moore foi uma inspiração para Bloomsbury; o Círculo de Viena desempenhou um papel indispensável no turbilhão intelectual que se seguiu à Primeira Guerra Mundial, seus aliados em Berlim eram parte integrante da Alemanha de Weimar, e não há necessidade de listar as credenciais de Wittgenstein. $\mathrm{O}$ Modernismo valorizou a austeridade, a pureza e o rigor; ele evitou a ornamentação e professou a indiferença, no que diz respeito a agradar seus leitores, com o objetivo de edifica-los, ao invés de agradá-los. Ele também considerou a Ciência como a conquista paradigmática e intelectual do ser humano e se viu como parte do empreendimento científico. Viu-se também incorporado em um ambiente acadêmico cuja profissionalização era crescente, para o qual uma lingua franca, capaz de estabelecer, entre outras coisas, as credenciais de seus participantes, era crucial. Coloque todos esses elementos juntos e você começa a perceber algumas das razões pelas quais os aspectos literários da escrita passaram a ser irrelevantes, se não hostis, ao empreendimento da Filosofia.

Isso não significa dizer que figuras como Bertrand Russell ou W.V.O. Quine não foram escritores talentosos; seus escritos, no entanto, não foram convencionalmente literários e - ao contrário dos escritos de, digamos, Wittgenstein seus objetivos estavam mais para a supressão de suas personalidades do que para promovê-las. Como os trabalhos científicos e os resumos ou análises de legislação, os quais foram seus modelos principais durante boa parte do último século, os escritos filosóficos tem como objetivo estabelecer verdades que sejam tão independentes quanto possível das particularidades e idiossincrasias de um autor. Esse tipo de impessoalidade, a qual requer um estilo que se apaga, permite que os escritos 
científicos descrevam experimentos que podem ser repetidos em diferentes circunstâncias, assim como textos legais que oferecem argumentos que podem ser aplicados em casos muito distantes de suas preocupações originais.

Um estilo que se apaga, entretanto, ainda é um estilo: o que ele não pode ser é um estilo individual. E ele é composto, eu penso, pelas técnicas que produzem tal estilo e não por elementos literários, em geral, que estão relacionados à suspeição na Filosofia. Agora eu penso que há partes da Filosofia nas quais uma abordagem impessoal tem seu lugar. Ela aborda problemas que, como sugeri, podem ser tratados independentemente dos autores que os apresenta, porque são inerentemente genéricos e de pequena relevância para a vida particular de seus autores. O que não tem lugar, no entanto, é o preconceito de que apenas a abordagem impessoal é legítima para tratar problemas filosóficos e, além disso, que apenas os problemas submissos a esse tipo de tratamento são legítimas questões filosóficas.

É por essas duas razões que tem sido difícil (mais em alguns casos e menos em outros) encontrar um lugar no cânone filosófico para figuras como Montaigne, Pascal, Schopenhauer, Kierkegaard, Emerson, Nietzsche e, novamente, Wittgenstein. Além de abordar problemas em Metafísica, Epistemologia ou Filosofia da Linguagem, esses filósofos parecem ter consciência de que, quando o assunto é questionar como se deve viver a vida - a questão de Sócrates, certamente uma legítima questão filosófica - a resposta dependerá do indivíduo, em particular, que está formulando a questão. Isso se dá uma vez que a questão é como fazer a vida valer a pena, dadas as características, necessidades, os desejos e habilidades específicos - e muito diferentes - que pertencem a cada um de nós, assim como as situações amplamente diferentes de cada indivíduo. Uma vez que a resposta a esta questão varia sistematicamente, dependendo de quem a está formulando, os filósofos, os quais eu estou discutindo frequentemente, oferecem autorretratos explícitos ou implícitos articulando suas próprias respostas, as quais não podem ser a resposta de nenhuma outra pessoa, mas pode, ainda, talvez, inspirar os outros a, por sua vez, olhar para suas próprias respostas.

Eu percebo que não disse nada sobre Descartes que, assim como Simon Critchley tão forçosamente nos lembra, desenvolveu um estilo próprio, mais pessoal; ou sobre Platão, que parece pertencer a ambos os grupos, ao mesmo tempo. Mas eu não quero tornar essa discussão mais longa do que ela já é; se alguém estiver interessado nós podemos discuti-los em outra ocasião. Eu também percebo que as classificações que eu ofereci aqui são imperfeitas e rudes. Estas são questões com as quais tenho me ocupado nesses dias, e eu estou sempre muito confuso sobre o que está predominante em minha mente.

Costica Bradatan: Eu penso que Alexander Nehamas levanta uma questão metafilosófica fundamental aqui. Parece-me que todo esse tratamento muito veemente da Filosofia como algo que não tem nada a ver com Literatura, deliberadamente ignorando os aspectos estilísticos do filosofar é, em si mesmo, sim, uma opção 
literária - uma de muitas possíveis. Escrever "sem estilo" é, certamente, uma escolha estilística; a recusa da Literatura é uma forma de Literatura, simplesmente como a iconoclastia trai um certo tipo de sensibilidade estética. Portanto, assim como sugere a genealogia de Alexander Nehamas, a declaração de guerra do filósofo analítico contra a característica literária da Filosofia poderia ser interpretada como uma espécie de manifesto literário radical. Mas, então, eu não posso evitar notar que os filósofos analíticos não fazem isso deliberadamente hoje, que geralmente não passa pelas suas mentes que seu estilo também é uma escolha literária e estilística. (Quando há somente uma forma válida de se fazer Filosofia, você não pode falar em escolha, pode?) Dessa forma, muito ironicamente, uma disciplina que foi então fundada na máxima "Conhece-te a ti mesmo", e que tem, através dos séculos, construído sua preocupação fundamental em torno do ensinar às pessoas o autoconhecimento, termina ignorando algo importante sobre sua própria natureza.

Giuseppe Mazzotta: Não está absolutamente claro que podemos concordar sobre o que constitui a "Literatura", e a história dos estudos literários é, notoriamente, marcada por debates intermináveis. Em nosso tempo, as tendências predominantes tem sido a Nova Crítica, a Desconstrução, o Novo Historicismo, os Estudos Culturais, os estudos de Gênero, etc. Todos eles pressupõem diferentes visões sobre os propósitos da Literatura e sua resistência a / cumplicidade com a hegemonia dos discursos e do gosto político e social. Com diferentes graus de convicção, entretanto, todas essas correntes críticas partilham de algumas preocupações: a linguagem literária (os textos de Homero, Lucrécio, Virgílio, Dante, Maquiavel, Shakespeare, Cervantes, Goethe, Tolstoy, Proust, etc.) é marcada pela criatividade e por um alto grau de autoreflexividade sobre a língua em si e suas ambiguidades.

$\mathrm{Eu}$ mesmo estou fortemente inclinado a concordar com filósofos / pensadores que compreendam as questões básicas estabelecidas pelos textos literários (Vico ou Nietzsche, Emerson ou Cavell) e elas variam de questões sobre autoridade e o eu a questões tais como conhecimento (ou não-conhecimento), imaginação, representação, verdade e ficção, sobre o valor da experiência humana, os dilemas sobre as crenças e a confiança, etc. Um diálogo inevitável ou monólogos de mal-entendidos existem entre as duas formas institucionais de pensamento. Dentro das instituições acadêmicas, com efeito, uma barreira de suspeições tem sido tradicionalmente erigida pelos filósofos em relação aos estudos literários e por estudiosos literários, em relação aos filósofos.

A suspeição dos filósofos pode, em parte, estar relacionada, eu receio, à maneira pela qual inúmeros estudiosos literários se engajam nos problemas filosóficos. Os críticos literários que "fazem" filosofia a partir de estudos literários agem como se estivessem impelidos a tornar a leitura de romances "relevante" para nosso tempo. Nesse processo, eles se apressam em encontrar em textos literários as formulações mais atuais de Lacan, Derrida, Foucault, etc. e perdem o escopo da especificidade de suas próprias disciplinas. Por outro lado, os próprios filólogos tendem a ser céticos e rejeitar todas as argumentações filosóficas da literatura. 
Costica Bradatan: Eu sou muito grato a Giuseppe Mazzotta por esta abordagem da questão da "Filosofia como Literatura" em termos dos estudos literários. É crucial, eu penso, analisar este tópico de diferentes ângulos e coloca-lo em uma perspectiva interdisciplinar mais ampla.

Aqui está minha próxima questão: se, conforme parecemos concordar, a Filosofia não trata "apenas de argumentos", mas é algo mais complexo do que isso, então valeria a pena articular um entendimento melhor e mais abrangente do que seja a Filosofia. Eu quero dizer, especificamente, um entendimento que incorpore as questões de retórica e estilo, de imaginação e "poeticidade", o papel estrutural das metáforas, a função fundamental da expressão e da expressividade. Não que algo similar não tenha sido feito antes. De fato, seria legítimo, eu penso, discutir uma tradição de filósofos que tenham, de forma recorrente, construído tais articulações. Vico e Nietzsche, para dar apenas alguns exemplos isolados, defenderam vigorosamente uma "Filosofia poética", por uma Filosofia enraizada nas noções de imaginação e criação. Entretanto, parece que cada geração tem de fazer isso por si mesma, para iniciar tudo novamente. Considerando-se que, em muitos círculos filosóficos contemporâneos, dizer "Filosofia poética" seria como dizer "círculo quadrado", como se pode argumentar de forma convincente em favor de uma Filosofia literária hoje? Se você tivesse de falar sobre isso para uma plateia reticente - talvez ligeiramente hostil - como você explicaria porque seria uma boa ideia trabalhar com essa noção de Filosofia mais abrangente? O que se ganha com ela? Em suma, como você defenderia hoje que a Filosofia não trata apenas de argumentos?

Giuseppe Mazzotta: Eu penso que a lacuna institucional entre "Literatura" e "Filosofia" é, realmente, um problema secundário. A concepção de Literatura como algo relacionado com o questionamento / representação do significado do eu, uma vida, as possibilidades do eu ou mundos possíveis, traz consigo a concepção de uma nova forma de filosofar e, portanto, alterando ideias fixas ou ficções da coerência filosófica abstrata. A relação - frequentemente vista como desentendimento - entre Literatura e Filosofia sempre foi circular - com ecos e ressonâncias de uma na outra (noções de sinais, tempo, local, história, amor, poder, beleza, decepções, loucura, morte ou o que Alexander chama "Estilo", como o modo de individualização, etc.). Não se pode experimentar nada além de um movimento para trás e para frente entre diferentes registros e discursos e, neste sentido, o fim da Filosofia tradicional, anunciado por Heidegger, já aconteceu. Ela é substituída pela mais antiga forma de abertura em perguntar e responder. É um modo que objetiva expandir nosso horizonte de vida.

A forma pela qual as instituições acadêmicas podem responder a essa mudança na maneira pela qual passamos a entender um trabalho de arte como produtor de sinais e verdades é, provavelmente, propondo outra vez algo similar ao enciclopedismo, um senso de diálogo com a pluralidade das disciplinas, cada uma das quais pode existir separadamente, entidades fragmentárias, e nenhuma das quais pode ser considerada como autônoma e completa. A questão de como produzir o cruzamento de limites contíguos e fronteiras permanece. Literatura e Filosofia, em suas diferentes formas, 
nos levam ao limite, aonde a lei está e para onde somos indagados a definir, redefinir e testar esses limites. Se tivéssemos espaço e tempo suficientes nós, provavelmente, teríamos de invocar a faculdade da imaginação como a força que resulta em associações e dissociações. A paixão por compartilhar e se comunicar está localizada nas ficções e utopias da imaginação (a qual, como todos sabemos, não é nem ilusória e nem real).

Alexander Nehamas: Eu gostaria de iniciar repetindo algo que disse em minha última fala. Eu realmente não estou confortável com a ideia de que a Filosofia e a Literatura devessem ser minuciosamente contrastadas, pelo menos em parte, porque a "Literatura" não é uma categoria puramente descritiva: ela é também, pelo menos em parte, avaliativa e considerar algo como sendo Literatura é, em certa medida, elogioso (embora nós também apliquemos o termo a textos que aspiram ser considerados como tais, mesmo que sejam de menor importância). Muitos textos filosóficos são, nesse sentido, literários: Descartes, Hume, Russell e Quine - entre outros - certamente poderiam ser qualificados como autores literários. Para mim, a diferença não está entre Filosofia e Literatura (e Giuseppe Mazzotta está certo em insistir que não podemos concordar facilmente sobre o que conta como Literatura), mas entre escritos que aspiram à impessoalidade e escritos que permitem a seu autor uma presença individual forte, às vezes, quase uma invasão. Pelas mesmas razões, eu sou cauteloso em relação ao termo "poético".

$\mathrm{Na}$ medida em que eu esteja certo, segue-se que há um lugar tanto para as abordagens pessoais quanto impessoais dentro da Filosofia em si - alguma filosofia pode, muito bem, ser apenas argumentos (embora, eu acredito que, pensar que somente argumentos são considerações filosóficas legítimas é adotar uma visão muito estreita do que seja a Filosofia). O problema, nos termos de hoje, está na ideia de que escritos pessoais não podem ser filosóficos. Mas porque essa ideia não está baseada em considerações puramente intelectuais (ela também depende igualmente de considerações institucionais) - por exemplo, a história da Filosofia analítica e a orientação intelectual de muitos daqueles que tem sido atraídos para ela - não é fácil apresentar "um argumento" de que a Filosofia não é apenas argumentos.

Uma maneira de abordar a questão é oferecer uma interpretação dos escritos pessoais de um filósofo que se conecta aos interesses daqueles que são a favor de uma abordagem exclusivamente argumentativa. Mas o perigo aqui é de que tais interpretações podem acabar ignorando o elemento pessoal, totalmente, e atribuir ideias surpreendentes ou banais aos filósofos envolvidos; eles então apresentam a resposta: "Bem, se isso é o que $\mathrm{X}$ está tentando dizer, não é novidade para nós - e isto poderia ter sido dito de forma muito mais direta". Então, à medida que a abordagem pessoal seja relevante para as ideias expressadas, é importante notar seu efeito em sua tessitura e o objetivo de aborda-la diretamente.

Outra abordagem, perfeitamente compatível com a primeira, é sugerir que o que caracteriza os escritos filosóficos, em geral, é um compromisso em fornecer razões para a visão de uma pessoa e que nem toda razão tem de ser um argumento. Pensar que seja assim, eu acredito, é trivializar a ideia de um argumento: construir uma figura 
(verbal) do eu seria a aceitação de determinados posicionamentos filosóficos e oferecer esta figura para inspeção - como Nietzsche, por exemplo, faz frequentemente parece-me uma forma de fornecer uma razão para (ou, para alguns, contra!) aceitar esses posicionamentos. Mas tal razão não é, estritamente falando, um argumento, uma vez que o fato de uma pessoa achar essa figura interessante ou não depende, pela própria explicação de Nietzsche, não apenas do conteúdo da figura, mas também do tipo de pessoa que seja. E, por mais que seja grosseiramente não-informativo (A é "saudável/forte", B é "doente/fraco") não há maneira de fazer uma descrição do tipo de pessoa que alguém seja, em termos específicos o suficiente, para nos permitir dizer algo do tipo "Se você for do tipo de pessoa assim, você achará a figura interessante; se não for, não achará", e usar isto, ou seja, como uma premissa de uma argumento.

$\mathrm{Eu}$ acredito que isso seja vago e, ao mesmo tempo, não é uma resposta direta à questão de Costica, mas espero que permaneça no escopo de análise das questões que estamos discutindo.

Costica Bradatan: Eu peço desculpas se tornei as coisas ainda menos claras do que eram antes. "Poético" pode, na verdade, significar muitas coisas. De fato, quando eu usei "Filosofia poética" eu estava brincando com o título de um dos livros de Giuseppe (The New Map of the World: The Poetic Philosophy of Giambattista Vico).

Simon Critchley: Eu gostaria de abordar duas questões, uma levantada por Costica e Giuseppe Mazzotta e a outra por Alexander Nehamas. A primeira diz respeito à ideia de "Filosofia poética". Deixe-me iniciar com uma anedota.

Eu não escrevo poesia. T. S. Elliot diz, em algum lugar, que os únicos poetas que devem ser levados a sério são aqueles que escrevem após a idade de 25 anos. Eu parei de escrever poesia aos 24 , em grande medida como consequência de minhas leituras de Auden. Ele parecia ser capaz de dizer o que quer que fosse que eu quisesse dizer da maneira que ele escolhesse. Eu decidi jogar a toalha. Como consequência, eu me tornei um leitor apaixonado por poesia. Minhas paixões poéticas aumentavam e diminuíam, mas o poeta pelo qual fiquei obcecado foi Wallace Stevens. Eu penso que a poesia de Stevens, em particular seus poemas longos, tardios e meditativos, como "An Ordinary Evening in New Haven", decisivamente remodela o que seja, indiscutivelmente, a preocupação fundamental da Filosofia, a saber: a relação entre pensamento e coisas, mente e mundo ou, na linguagem de Stevens, imaginação e realidade. Mas o que é crucial é que eles a escrevem em formato poético, como um poema. Quando Stevens tentou escrever Filosofia, o que ele fez em um trabalho intitulado "A Collect of Philosophy", os resultados foram, na melhor das hipóteses, incoerentes, e eu acredito que o artigo tenha sido rejeitado pela Mind, e com razão. O que Stevens era capaz de desenvolver era uma voz meditativa única que usava o formato poético a fim de desenvolver pensamentos completos: teses, hipóteses ("se" era, provavelmente, a palavra favorita de Stevens), ruminações e aforismos que se poderiam denominar filosóficos.

Algumas consequências surgem a partir daí: 
1. Eu não acredito que o que Stevens estava fazendo pudesse ser descrito como "Filosofia poética" (ou mesmo "poesia filosófica", embora esta estivesse mais próxima da verdade). É poesia preocupada com uma questão (a relação entre a mente e o mundo, digamos) que é também uma preocupação dos filósofos. Mas a forma de expressão é vitalmente diferente e essa diferença tem de ser respeitada.

2. Isto levanta a questão de como se escreve sobre poesia sendo um filósofo. Giuseppe Mazzotta coloca seu dedo em uma tendência repugnante, que é o uso de poesia ou Literatura para confirmar bocados geralmente mal digeridos de Lacan, Derrida ou quem quer que seja. Isto é poesia reduzida ao status de um exemplo para ilustrar alguma teoria. Eu penso que o procedimento deveria ser precisamente revertido. Não é uma questão de se usar uma teoria para explicar um poema simplesmente a fim de confirmar aquela teoria. Não se trata também de parafrasear ou explicar a expressão poética de certa forma obscura em um formato filosófico claro. É muito mais uma questão de tentar ler um poeta cuidadosamente a fim de apontar na direção de uma experiência da mente, da linguagem e do mundo que seja mais bem expressada poeticamente. Toda a dificuldade consiste na natureza do apontar na direção de: como alguém escreve sobre poesia sendo um filósofo de forma que não afogue o poema em conceitos estranhos a seu modo de expressão. Nesse sentido, não é uma questão de "Filosofia poética", mas sim uma tentativa filosófica de transmitir uma experiência do pensamento que acontece poeticamente. Isto requer algo como "tato".

A segunda questão diz respeito à relação impessoalidade versus pessoalidade na Filosofia e a descrição de Alexander Nehamas de uma suspeição contemporânea acerca de um estilo pessoal nos escritos filosóficos. Eu gostaria de ligar isto aos efeitos da profissionalização na Filosofia. Como todos sabemos, era lugar comum na Antiguidade, e por muito tempo após a Antiguidade, afirmar que a Filosofia era algo transformador ou questionador do que significa ser o eu. Como considera Hadot, a Filosofia era uma maneira de vida. Como consequência, foi difícil, no caso de um Sócrates ou de um Epicuro fazer a separação entre a Filosofia e a vida. Eu afirmaria que o apelo de pensadores como Nietzsche, Heidegger, Arendt ou Foucault não está apenas no fato que alguns deles viveram vidas interessantes, mas no fato que são pensadores para os quais a Filosofia teve um efeito transformador, um efeito que está vivo em seus leitores.

Costica Bradatan: Como isso se relaciona com a questão da profissionalização?

Simon Critchley: Em seu livro sobre Edith Stein, Alasdair MacIntyre escreve,

Aprisionar a Filosofia dentro das profissionalizações e especializações de um currículo institucionalizado, assim como fizeram nossas culturas contemporâneas europeia e Norte-Americana, é indiscutivelmente muito 
mais efetivo em neutralizar seus efeitos do que mesmo a censura religiosa ou o terrorismo político.

O efeito da profissionalização da Filosofia está no sentido em que ela não importa e nem deveria importar para a condução da vida de uma pessoa. A Filosofia deveria aspirar à impessoalidade da Ciência Natural. Nada mais. A Filosofia é uma disciplina acadêmica tecnicamente complexa com seu próprio critério interno de excelência e deveria ser mantida afastada de outras disciplinas humanísticas e da indecorosa desordem das vidas privadas e públicas. Esta é a visão que eu gostaria de desafiar.

Incidentalmente, há filósofos que poderosamente adotam um estilo pessoal em seus escritos, como Nietzsche. Mas também há filósofos que adotam um estilo altamente impessoal, o qual está devidamente ligado ao modernismo como destaca Alexander Nehamas, como, por exemplo, nos primeiros escritos de Wittgenstein. Mas o estilo pessoal de Nietzsche e o impessoal de Wittgenstein são ambos formas de se expressar cujas intenções tem um profundo efeito existencial em seus leitores. Então, há filósofos, como Ayer, que fariam uma distinção radical entre a Filosofia, entendida como análise conceitual, e "o todo da vida", como Ayer disse a Berlin nos anos de 1930. Eu suponho que minha objeção seja com relação àqueles filósofos que não se preocupam com a dimensão existencial dos escritos filosóficos.

Desculpem-me pela extensão desta resposta. Eu não tenho certeza se ela limpa a água ou a deixa mais turva.

Costica Bradatan: Eu estou contente porque tanto Alexander Nehamas quanto Simon Critchley trouxeram para o debate o tópico da Filosofia como uma arte de viver, pois minha próxima questão será sobre algo intimamente relacionado a este tópico: a "criação do eu". Com uma história que remonta a, digamos, Sócrates, a noção de que o eu não é algo com o qual nascemos, mas algo que constantemente criamos e recriamos é um dos tópicos favoritos da modernidade filosófica. Eu sei que cada um de vocês já trabalhou - ou pelo menos tocou em - com este tópico em seus trabalhos. Em The New Map of the World, Giuseppe Mazzotta examina a presença do tópico em Vico, para quem "não há nenhuma essência a priori para o eu: uma pessoa é o que faz de si mesma, e uma pessoa faz de si mesma o que sabe, de forma que ser, conhecimento e fazer estão incessantemente inter-relacionados em uma recirculação sem fim" (27). Em certo sentido, o eu de um autor é o resultado dos livros que escreve; os livros que Vico escreveu o tornaram quem ele era, eles o "escreveram" de certa forma: "a Nova Ciência o faz, lhe dá autoridade, pelo menos na mesma proporção que ele produz a Nova Ciência" (18). Seria, portanto, legítimo falar em "uma história do eu" em Vico, de um eu estruturalmente aprisionado na lógica da historicidade, ou, como Giuseppe o coloca, um "subjectum... literalmente jogado, sem uma fundação sólida, perdendo controle de si mesmo e provisoriamente sem consciência" (19). Recuperar o controle sobre o eu, para coloca-lo de pé, é um projeto de toda uma vida. Aquele que entra em tal projeto de importância tem algo de artista na busca pelo magnum opus. O processo de criar um eu único para si mesmo torna-se, dessa forma, uma arte muito difícil e exigente (na Gaia Ciência Nietzsche exclama: "o 'dar estilo' ao personagem de alguém 
- uma grande e rara arte"!). No limite, mesmo a morte de uma pessoa pode ser empregada em seu projeto de moldar um eu. Como Simon Critchley coloca essa questão em seu Very Little ... Almost Nothing, "a autenticidade individual se produz através de atos de auto-invenção e auto-criação, pelos quais a morte se torna meu trabalho e o suicídio se torna a possibilidade mais atual - ergo o suicídio lógico de Kirilov" (25).

Agora, se nós decidirmos ver a criação do eu como o propósito central de um projeto para a vida toda, então, a Filosofia - na responsabilidade que assume do "cuidado com o eu" - passa a adquirir algumas das características deste projeto criativo: ela se torna, por sua vez, uma atividade criativa (neste sentido podemos, provavelmente, falar de uma "Filosofia Poética "). Como tal, vista deste ângulo em particular, o tema de nossa questão especial - Filosofia como Literatura - torna-se de grande importância. A ligação entre as duas não é algo acidental, mas algo embasado em uma visão mais ampla da condição humana e sua ontologia. Da mesma forma, o filósofo que adota a visão de que a criação do eu deveria ser nossa tarefa mais importante não é diferente de um autor de ficção, alguém cujo trabalho é criar "personagens", multiplicar o "eu". Este é um dos pontos centrais que Alexander Nehamas defende em seu livro The Art of Living. A criação do eu é, para ele, igualmente uma conquista literária e filosófica: "É uma conquista filosófica porque o conteúdo e a natureza do eu criado no processo ... depende da defesa de pontos de vista sobre questões que, tradicionalmente, tem sido consideradas filosóficas... É literária porque a conexão entre esses pontos de vista filosóficos não é apenas uma questão de inter-relações lógicas e sistemáticas mas também, de forma mais central, uma questão de estilo" (3). Nesta perspectiva "estética", criar um eu é ser bem sucedido em se tornar alguém, em se tornar um personagem, ou seja, alguém incomum e distinto (4). Como resultado, "os filósofos da arte de viver" aos quais Alexander se refere em seu livro (Foucault, Nietzsche), assim como aqueles os quais ele apenas menciona de passagem (Pascal, Schopenhauer, Kierkegaard, Emerson, Thoreau e, "em pelo menos uma leitura", Wittgenstein) são, ao mesmo tempo, figuras geralmente consideradas sempre que o tema da "Filosofia como Literatura" surge.

À luz destas (talvez um pouco extensas) considerações, uma questão fundamental surge, a qual eu estou propondo para discussão: se a tarefa majoritária da Filosofia é participar em uma literária "criação do eu", qual seria o papel de tais noções (preeminentemente) literárias como narração, gênero, ponto de vista autoral, tropos e enredo na produção de um discurso filosófico?

Eu estou, é claro, ciente de que esta é uma questão muito ampla e que se torna difícil, nesta conversa, de se chegar a qualquer ponto além de um mapeamento básico de um território muito complexo.

Alexander Nehamas: Eu certamente concordo com Costica que "a criação do eu" está, se não como $a$ principal, entre as tarefas principais da Filosofia. Ela está também entre as tarefas principais de outras práticas e disciplinas e, de qualquer forma, a Filosofia tem espaço para muitos outros projetos, que tem pouca relação direta com a 
autocriação. O ponto primordial, para mim, no entanto, é que - como tenho tentado sugerir em nossa discussão até o momento - o contraste relevante não está, primeiramente, entre um tipo de Filosofia literária e outro não literário. Toda a Filosofia é, em sentido amplo, literária a partir do momento em que é escrita. Mas parte da Filosofia é escrita no que tenho chamado de um estilo pessoal e outra parte em um estilo que aspira a impessoalidade. É verdade que em The Art of Living - na exata passagem que Costica cita em sua questão - eu realmente apelo à "Literatura", mas começo a pensar que isto tenha sido um erro.

Ademais, em meu entendimento, nem todo filósofo com um estilo distinto, pessoal assume o que chamo de uma abordagem "estética" para a autocriação. Por exemplo, em seus trabalhos de "meados" e do "fim" de sua carreira (tudo que seus diálogos Socráticos, os quais são, para dizer o mínimo, ambíguos), Platão apresenta um eu (ele o chama de "Sócrates" ou "o filósofo") que ele acredita ser profundamente verdadeiro para a natureza humana em geral. Da mesma forma, ele o oferece como um modelo de emulação para todos: à medida que alguém falha em realiza-lo, esta mesma pessoa falha como um ser humano. Em oposição, os filósofos estéticos se apresentam como personagens que não podem ser diretamente emulados: tentar realizar tal coisa resultaria - à medida que isto pudesse ser, absolutamente, bem sucedido - na produção de uma cópia de seus originais. Mas isto seria perder, de uma vez por todas, o foco de seus trabalhos, que seria oferecer a si próprio como inspiração para outros poderem modelar-se de sua própria maneira, com base em suas circunstâncias particulares, o que é diferente para cada indivíduo e, por esta razão, torna a imitação direta de outra pessoa, em último caso, impossível.

Em qualquer caso, a resposta curta à questão final de Costica parece-me ser que não é possível estabelecer em termos gerais o papel de variados aparatos literários em um projeto filosófico da autocriação - não mais, quer dizer, do que seja possível estabelecer tal afirmação geral sobre qualquer gênero literário. Por exemplo, o trabalho de Robert Browning "A Grammarian's Funeral Shortly after the Revival of Learning in Europe", parte do qual eu cito abaixo, depende crucialmente de metáforas de altura e profundidade, de luz e sombra, montanhas e vales, zona urbana e zona rural, a fim de estabelecer o respeito e a admiração dos estudantes do gramático:

Vamos começar a carregar este cadáver,

Cantando juntos.

Deixemos os lugares comuns, os torpes vulgares

Cada qual em sua corrente

Dormindo seguro no coração da planície,

Cuidada até o cantar do galo:

Cuidado se acolá não é dia novamente

Guarnecendo até o galo-corvo!

Aquele é o país apropriado; lá, o pensamento do homem,

Mais raro, mais intenso,

Auto-coletado para uma erupção, como deveria ser,

Aquece no turíbulo.

Deixemos à iletrada planície seu rebanho e sua colheita;

Sobre poetas e pensadores: uma conversa sobre filosofia, literatura e a reconstrução do mundo - Costica Bradatan; Simon Critchley; Giuseppe Mazzotta; Alexander Nehamas. Tradução por Djeissom Silva Ribeiro. 
Procuremos sepultura

Em uma alta montanha, lá em cima,

Repleto de cultura!

Todos os picos se elevam, mas um se sobressai em relação aos restantes;

As nuvens o ultrapassam;

Não! Aquela centelha é a da cidadela

Circulando seu topo.

Do outro lado está o nosso caminho; nos leva serpenteando até o alto:

Vós esperais o aviso?

Nossa vida inferior era em nível e na noite;

Ele está para a manhã.

Passo para uma melodia, arcas quadradas, erigem cada cabeça,

Avisem os espectadores!

Este é nosso mestre, famoso, calmo e morto,

Suportado em nossos ombros.

C. P. Cavafy, no entanto, abordando um tema surpreendentemente similar em "Tomb of the Grammarian Lysias", o faz sem metáforas ou qualquer tropo literário óbvio:

Na biblioteca de Beirute, bem à direita quando você entra, nós enterramos o sábio Lysias, o gramático.

O local é muito apropriado.

Nós o colocamos próximo àquelas suas coisas

das quais ele talvez se lembre mesmo lá:

notas, textos, comentários, variantes,

todos os tipos de estudos das expressões idiomáticas gregas.

Também, dessa forma, uma vez que passamos em nosso caminho para os livros,

nós veremos e homenagearemos sua sepultura.

Eu acredito que este seja apenas um pequeno exemplo, mas o ponto geral parece-me inegável: nenhuma dessas generalizações são possíveis.

Costica Bradatan: E com relação, então, à "criação" do eu?

Alexander Nehamas: Deixe-me passar a uma questão levantada através da afirmação por Giuseppe Mazzotta que Costica cita em sua questão, com relação ao efeito de que o eu de um autor é o resultado dos livros que ele escreve e que os livros que Vico, em particular, escreveu o tornaram quem ele era e que, de certa forma, eles o "escreveram": "A Nova Ciência o faz quem ele é, dá-lhe autoridade, pelo menos na mesma medida em que ele produz a Nova Ciência”. Eu penso que isto está totalmente correto. Mas eu também estou consciente do fato que muitas pessoas estão convencidas que existe uma enorme lacuna entre "o trabalho" e "a vida", Filosofia e 
realidade - uma lacuna que isola a Filosofia da autocriação em um domínio de pura especulação e retira dela qualquer significado para além de seu conteúdo teórico.

Este perigo pode parecer mais claro no caso de Nietzsche. Nietzsche, que uma vez escreveu que "se você comparar Kant e Schopenhauer com Platão, Spinoza, Pascal, Rousseau e Goethe, em relação a seus espíritos e não as suas mentes, então, os primeiros estão em desvantagem: seus pensamentos não constituem uma história apaixonada do espírito; não há nada aqui que daria um romance, nenhuma crise, nem catástrofes ou cenas de morte; seus pensamentos não são ao mesmo tempo uma biografia involuntária de um espírito", fez de seu próprio trabalho nada além de uma "história apaixonada de seu espírito". Mas Nietzsche, como sabemos, levou uma vida modesta, infeliz e não realizada; atormentada por doenças, solidão e falta de reconhecimento - que se revelou para a maioria das pessoas extremamente diferente da vida elogiada em seus escritos e a qual finalmente ele afirma ser a sua em Ecce Homo. De fato, ainda é muito comum considerar os títulos das seções daquele livro - "Por que eu sou tão sábio", por exemplo, ou "Por que eu sou um destino" - simplesmente como sinais de sua loucura em estágio inicial. Pense em Miguel de Unamuno, que caracterizou a Filosofia de Nietzsche como "a doutrina dos fracos que aspiram a ser fortes", e via o próprio Nietzsche como o tipo exato, "escravo", contra quem a Genealogia da Moral foi escrito. Ou considere que um autor norte-americano contemporâneo se encontra tão triste e em estado deplorável que confesse que "não desejaria a vida que Nietzsche viveu para ninguém, nem mesmo para Rousseau!". Eu devo confessar que eu também expressei um ponto de vista dessa natureza em meu livro sobre Nietzsche quando eu separei "o homem" do "trabalho" e afirmei que "ao concordar com seus trabalhos, nós não estamos concordando com o pequeno homem miserável que os escreveu, mas com o filósofo que emerge através deles, o personagem magnífico que esses textos constituem e manifestam o agente que, uma vez que o desejo de poder permanece, não é nada, mas seus efeitos - ou seja, seus escritos".

Mas isto é um erro terrível. A distinção entre "o pequeno homem miserável" e o "magnífico filósofo" - "o homem" e "o trabalho" - exige que pensemos "a vida" como tudo que faz parte da biografia de alguém exceto seu trabalho! Isso, por sua vez, é pensar "o homem" como a pessoa que produziu o trabalho, de forma isolada daquele trabalho, como se o trabalho de alguém fosse uma parte menos importante da vida do suas contas a pagar, as refeições e as conversas casuais, as doenças e decepções que são suas acompanhantes inevitáveis. É um erro ainda pior quando "o homem", como Nietzsche e os filósofos que estamos discutindo aqui, é tão devotado a "o trabalho" que ele subordina o restante de sua vida a ele. Não - o trabalho de um filósofo é uma parte integral de sua vida: você não poderia "desejar a vida que Nietzsche viveu" para quem quer que seja sem, necessariamente, dar àquela pessoa a parte mais importante da vida de Nietzsche: sua própria filosofia. Isso, eu penso, é o que a afirmação de Giuseppe traz tão claramente para nossa percepção.

Costica Bradatan: Eu devo me desculpar com Alexander por retornar, repetidas vezes, às mesmas coisas e por ficar girando em torno do mesmo tópico da Filosofia 
como Literatura. Parece que o tópico desta questão que estou editando deve ter vindo a se tornar uma obsessão para mim. Muito provavelmente, esta questão tenha, por sua vez, começado a me "editar".

O que me atraiu, particularmente, para a noção de uma criação "literária" do eu (como apresentada por Giuseppe em seu livro sobre Vico e por Alexander em The Art of Living) foi, precisamente, a promessa implícita de que o eu "miserável", com todas as suas refeições e contas a pagar, com sua enfadonha rotina diária, pode estar, de alguma forma, "dissolvido" no eu "magnífico". Se essas palavras não foram exageradas, poder-se-ia dizer que o último pode, sob certas circunstâncias, "redimir" o primeiro. Se eu não estiver enganado, esta é uma lição que podemos extrair de uma das estórias curtas de Borges. (Eu tenho certeza que todos vocês conhecem a estória, mas vale a pena relembrar aqui.). Este texto, que em seu original em Espanhol traz um título em Inglês (Everything and Nothing), é sobre a busca de Shakespeare por um eu, por ele mesmo, e no final é sobre a morte de Shakespeare. Esta estória curta (que começa com: "Não havia ninguém nele..."), termina com a seguinte frase: "A história acrescenta que antes ou depois de morrer, ele se descobriu em pé diante de Deus, e disse a Ele: Eu que fui tantos homens em vão, gostaria de ser um, de ser eu mesmo. A voz de Deus o respondeu vindo de um redemoinho de vento: Eu, também, não sou eu; eu sonhei com o mundo assim como você, Shakespeare, sonhou com seu próprio trabalho, e entre as formas de meus sonhos está você, que como eu é muitos, embora nenhum".

Eu estou ciente que isto não contribui muito para abordar o ponto destacado por Alexander sobre a necessidade de realmente cuidar daquele eu apanhado na insignificância da vida cotidiana, mas, pelo menos, ele aponta para uma perspectiva ligeiramente diferente. Se nós não parecemos ser muito, nós não deveríamos estar muito preocupados com isso: simplesmente como Deus, nós temos essa peculiar habilidade de ser mucho y nadie ao mesmo tempo.

Giuseppe Mazzotta: Há uma frase na resposta de Alexander Nehamas que eu acho particularmente impressionante. Alexander está se referindo à "lacuna" que parece emergir entre "o trabalho" e "a vida" de um autor, "Filosofia" e "realidade", e esta lacuna "relega" a questão da autocriação filosófica ao domínio da pura abstração. Ele avança e argumenta muito convincentemente sobre o erro que é separar a vida dos trabalhos.

A frase cristaliza, para mim, o que tem ocorrido em nossa conversa, incluindo, até mesmo, as preocupações com as estruturas disciplinares, a fronteira entre Filosofia (ou Literatura) e a vida, e Filosofia e Literatura, amplamente discutida por Simon e Alexander. As analogias entre as formas de pensar o eu e os argumentos que afirmam que a Literatura há muito já morreu (ou o "fim do homem"), e entre a maneira que concebemos (e nos preocupamos com) a fragmentação de nossas disciplinas, ou nos perguntamos sobre o compromisso, em particular com nossa área, são transparentes.

$\mathrm{Eu}$ valorizo muito o mero desejo de fazer com que a Literatura e a Filosofia sejam, elas mesmas, inseridas em nossas vidas, e a um nível visceral penso que as afirmações de Heidegger (e Foucault e Derrida) sobre o "fim do homem" sejam tanto 
absurdas quanto interessantes. O que estas frases - fim do homem, fim da Literatura sugerem é a necessidade de reconstruir nossos mundos, de reconceitualizar a ideia de "nosso" mundo, uma atividade que considero anterior a encontrar o lugar do eu no mundo.

A metáfora da "lacuna" recorda, propriamente falando, uma divergência ou hiato mais do que uma fronteira, algo difícil e talvez impossível de alcançar para a vida de uma pessoa e seus trabalhos ou disciplinas. Mesmo se nós promovermos ideais de comunicação dentre a humanidade, ou sua unificação, nós não podemos, na realidade, cancelar as fronteiras, preencher as lacunas ou encontrar a verdade suprema sobre alguém. Segue-se que nós podemos pensar no eu (ou a compartimentalização de disciplinas e, para esta questão, das nações do mundo) ao expor a natureza fragmentária e incompleta de nosso ser.

Tanto Simon quanto Alexander com razão insistem que a Filosofia precisa pensar a partir da perspectiva do não lugar da Literatura e "traduzir" esse pensamento em uma multiplicidade de outras línguas e estilos. Tudo isso pode, simplesmente, significar que a lacuna pode nos ajudar a identificar nosso lugar no mundo.

Costica Bradatan: Eu gostaria de aceitar a sugestão de Giuseppe e focar a próxima questão nesta noção de "reconstrução" do mundo. Esta é, de fato, uma ideia que tem sido o assunto de vários livros de Giuseppe ( The New Map of the World, o qual eu já mencionei, assim como Cosmopoiesis e The World at Play), e eu estou propondo isto agora porque parece haver alguma temática em comum aqui: tanto Simon quanto Alexander lidaram, de suas maneiras específicas, com esta questão, ou pelo menos a tocaram, em seus trabalhos. O que - se eu não estiver completamente enganado Simon faz em seu Infinitely Demanding é uma "reconstrução" do mundo político através de uma "ética do compromisso", assim como o que Alexander faz em Only a Promise of Happiness pode ser visto, em um sentido, como uma "reconstrução" do mundo através de uma recuperação da noção de beleza. Portanto, eu gostaria de propor para discussão a relação entre Filosofia, Literatura e a "reconstrução" do mundo.

Simon Critchley: Por meus pecados, eu estou ensinando o trabalho completo do livro Ser e tempo de Heidegger este semestre e, na terça-feira, eu tentei esboçar seu conceito de mundo, em termos da distinção categorial que ele promove entre maleabilidade e disponível, ou o conveniente, utilmente pragmático e a contemplação teórica das coisas como objetos em contraponto ao sujeito. Obviamente, Heidegger favorece o primeiro em detrimento do segundo. Mas ao subtender ambas as categorias ele afirma que Dasein é a mundanidade do mundo, especificamente que o ser humano é a condição de possibilidade a priori para a existência de um mundo, em absoluto. Isso culmina naquilo que vejo (outros discordam) como a tese idealista de que não haveria um mundo sem Dasein, ou não haveria um mundo sem um eu para quem esse mundo seria tal e qual.

O que quer que alguém compreenda dessa afirmação, eu penso que essa posição está ainda mais fortemente articulada por Wallace Stevens em "The Idea of Order at Key West", que é uma meditação sobre a natureza do processo da criação 
poética. É um poema dialogado no estilo Coleridgeano, com dois personagens, Ramon Fernandez e a voz poética, o 'nós' que observa um personagem ao qual se refere simplesmente como 'ela'. Stevens escreve,

Ela era a única artífice do mundo

No qual ela cantava. E quando ela cantava, o mar, Qualquer personalidade que ele tivesse, tonava-se o eu Que era sua canção, porque ela era a criadora. Então, nós, Ao passo que contemplávamos sua caminhada, lá, solitária,

Sabíamos que nunca houve um mundo para ela

Exceto aquele que ela cantava, e cantando, o criou.

Às vezes, eu penso que isso está absolutamente correto. É certamente bonito. As palavras do mundo são a vida do mundo e nós criamos um mundo em palavras ou construímos um mundo como Costica indaga. Remova essas palavras, em especial, remova a nós todos e não haverá um mundo significativo.

Mas, então, novamente o problema que se coloca é como lidar com uma realidade independente do "sujeito": crua, natureza física bruta, todos os 13 bilhões de anos disso. Em minha leitura, este é o problema que Stevens aborda em seus poemas tardios, por exemplo em "Not ideas about the thing, but the thing itself'. A saber, como podemos iniciar a concepção da coisa em si mesma, da natureza pura e dura? Eu penso que isso leva Stevens - e alguns outros poetas também, eu penso em Pessoa em direção a um tipo de anti-poesia, uma poesia de uma realidade material a qual a poesia não pode capturar...

Estamos condenados a oscilar entre o idealismo e o realismo sem fim? Muitos filósofos acreditaram que haviam resolvido essa questão. Eu continuo cético.

Giuseppe Mazzotta: Quase todo pensador significativo durante os últimos cinquenta anos, aproximadamente, tem tentado dar uma reinterpretação mais ou menos explícita da noção do "mundo", a partir do mundo familiar no qual nos encontramos até o mundo público o qual compartilhamos - o mundo como um contexto de significação compartilhada. Pode-se pensar no sentido do "mundo", de Heidegger; nas utopias marxistas e nos esquemas do Iluminismo acerca da liberdade. Pensemos nisto, este gênero remonta à utopia de Platão e à atualização do Renascimento sobre seu mito (More, Campanella, Bacon, etc. com suas percepções em perspectiva e sobre como o espaço pode ser manipulado), e todos eles procuram enfrentar os velhos modelos aristocráticos ou simplesmente despir-se de valores existentes em seus acréscimos.

Parafraseando Marx, pode-se dizer que, mais do que interpretar o mundo, muitos pensadores/intelectuais recentes tem tentado reinventar um aspecto do "mundo": a questão dos limites ou fronteiras. A suposição por trás desta direção do pensamento é que o mundo não é uma concepção ou lugar estático. Um lugar pode ser transformado e pode ser cientificamente construído. Um caso recente sensivelmente dramático de tal configuração emergente de "mundo" é o Empire de A. Negri (uma mistura de utopias marxistas, spinozistas e deleuzianas) nas quais ele realmente 
imagina um mundo sem fronteiras. Nenhuma transgressão possível é capaz de existir em tal imagem do mundo e, com efeito, Negri coloca entre parêntesis, completamente, o aspecto potencialmente trágico desta fantasia: um mundo sem limites ou fronteiras pode ser facilmente pensado como engendrador do caos e da violência devastadora, os textos trágicos revelam constantemente. $\mathrm{O}$ mito bíblico da confusão de línguas em Babel é uma metáfora destacada desta possibilidade.

Em sua maior parte, entretanto, a re-conceitualização do mundo, em andamento, enfoca todos os limites, questiona-os e renegocia-os. Os limites estão relacionados aos sexos (e as fronteiras dentre cada um deles), países, classes sociais, línguas, religiões, ética (seres humanos e animais), a relação entre as artes e ciências, literatura e filosofia, etc. Ao contrário do que se possa pensar (eu tenho, frequentemente, pensado em minha própria disciplina de forma depreciativa), os estudos literários tem sido levados ao primeiro plano dessas preocupações (especialmente as teorias de gênero e o neo-historicismo). Os romances latinoamericanos e indiano-ingleses inauguraram esse modo. A teoria da translação de Benjamin (ou da "diferença" de Derrida), para mencionar alguns exemplos, mostra o desejo dos filósofos de esclarecer nossas práticas e crenças.

Se um entendimento "global" emerge ou não dessas reflexões críticas é, necessariamente, uma questão discutível. E os limites (políticos, religiosos, biológicos, etc.) continuam se impondo.

Alexander Nehamas: Este é um gesto completamente irresponsável, uma reação não primeiramente à questão de Costica, mas à resposta em movimento de Simon. Dizer que, talvez, não haveria mundo algum sem um sujeito não é deslizar para um idealismo, se nós considerarmos "o mundo" como não sendo "natureza bruta", mas o espaço físico/cultural/social/conceitual dentre o qual nós vivemos nossas vidas reais. Esse mundo (eu, nem mesmo, vou fingir que conheço Heidegger bem o suficiente para atribuir-lhe essa posição, embora pareça correto) é um produto conjunto do que quer que seja o universo e das interações dos seres humanos com esse universo. Mas não houve o primeiro momento quando o universo estava transformado em um mundo: o mundo esteve sempre lá, como a cultura, a sociedade e a língua. Então, a interação é sempre entre os seres humanos e o mundo no qual nos encontramos (somos jogados para dentro dele?) e, portanto, ele está sempre em processo de reconstrução: a reconstrução é inevitável e todos estão engajados nela o tempo todo; a questão é de que forma as ações individuais de uma pessoa contribuem para isso.

$\mathrm{Eu}$, frequentemente, penso na beleza neste contexto, por duas razões. Primeiro, embora não seja uma propriedade "objetiva" das coisas, a beleza não é uma característica puramente "subjetiva" do observador, também. Pelo fato de ela não ser puramente subjetiva, nós podemos discutir sobre isso; e pelo fato de ela não ser puramente objetiva, nós não podemos nunca esperar alcançar uma concordância universal sobre qualquer julgamento estético. (Se nós pudéssemos, eu penso, nós estaríamos ocupando um mundo muito triste). 
Em segundo lugar, porque quando achamos algo bonito nós nos envolvemos em querer estar devotados, pelo menos (e, na maioria dos casos) parcialmente, a essa coisa e a passar parte de nossa vida em sua presença e companhia. Mas ao fazê-lo - aqui eu posso somente afirmar dogmaticamente o que eu tento defender em Only a Promise of Happiness - nós também nos envolvemos em mudar a nós mesmos e, neste processo, mudar a coisa bonita, não importando se for uma pessoa ou objeto. $\mathrm{O}$ resultado final é que a beleza pode apoiar o fato de que "o mundo" é um produto tanto do mundo que já está aí e de nossa própria contribuição; ela pode também aludir à constante mudança na qual consiste a reconstrução. Ademais, uma vez que nós não sabemos o que acontecerá conosco como resultado de nossa interação com algo que nós achamos bonito, a beleza, por sua vez, indica os perigos inerentes a cada esforço de reconstrução - perigos que nós não podemos evitar, uma vez que, como acabei de dizer, a reconstrução é inevitável para cada um de nós.

Costica Bradatan: Ao passo que ainda há coisas importantes as quais eu gostaria muito de discutir com você, por razões de espaço eu receio que nós tenhamos de terminar essa conversa. Eu espero que tenhamos outra oportunidade de retornar, algum dia, a algumas dessas questões que nós abordamos aqui, assim como levantar novas questões.

Dá-me satisfação dizer que esta foi uma conversa muito iluminadora, uma discussão fascinante e eu tenho certeza de que os leitores de The European Legacy vão concordar comigo neste ponto. Foi para mim uma grande honra e uma experiência muito enriquecedora fazer a moderação desta discussão. Simon, Giuseppe e Alexander: eu agradeço muito a vocês! 